\title{
Software educativo para seleção de materiais utilizando a metodologia de ASHBY
}

\section{Educational software for material selection using ASHBY Methodology}

\author{
1 Ricardo Abreu Lima de Souza adm.ricardoabreu@gmail.com \\ 2 Alexandre Alvarenga Palmeira \\ 3 Carlos Eduardo Abreu Lima de Souza \\ 4 Jorge João Ferreira de Souza Júnior \\ 5 Duílio Norberto Ferronatto Leite

\footnotetext{
Administrador, Dicente do Mestrado Profissional em Materiais UNIFOA

Professor Doutor, Docente do Mestrado Profissional em Materiais - UNIFOA

Enfermeiro, Dicente do Mestrado Profissional em Materiais UNIFOA

Engenheiro, Dicente do Mestrado Profissional em Materiais UNIFOA

5 Engenheiro, Dicente do Mestrado de Materiais da UFF
}

\section{Resumo}

O objetivo deste trabalho é realizar uma breve introdução ao mundo da seleção de materiais para elaboração de um projeto mecânico, as necessidades existentes em um projeto e como ponderar as escolhas por meio de um software educativo de simples utilização que foca na apresentação dos materiais metálicos, aplicando a metodologia de Michael F. Ashby. Essa metodologia é ressaltada no software, pelo cálculo do índice de mérito e outros passos que visam clarificar o projetista diante de seus objetivos de aplicação. A programação do software foi realizada em MatLab R2015b, utilizando-se a ferramenta GUI (Graphical User Interface) para criação das telas, juntamente com algoritmos que formam o corpo do programa que possibilitam a leitura dos dados inseridos pelo usuário, criação dos bancos de dados, ativação de botões e organização das informações. Finalmente, para demonstrar a aplicação e o objetivo do software, é apresentado um estudo de caso de seleção de material para revestimento de cabides para roupas. O que comprova a aplicabilidade do produto para a seleção do material adequado.

\section{Palavras-chaves:}

Ashby; SM; MatLab; GUI; PDP.

\begin{abstract}
The objective of this work is to make a brief introduction to the world of selection of materials for the preparation of a mechanical design, the existing requirements on a project and how to weigh the choices through an educational software and simple to use that focuses on the presentation of metallic materials applying the methodology of Michael F. Ashby that is highlighted in the software by calculating the figure of merit and other steps. The development of the software was using MatLab R2015b, using the GUI tool (Graphical User Interface) for creating the screens and along with algorithms that form the program the body to the reading of user input, creation of databases, activation buttons and organization of information. Finally to demonstrate the application and purpose of the software is presented a case study consisting of material selection for rack coating for clothes.
\end{abstract}

Keywords:

Ashby, SM, MatLab, GUI, PDP.

\section{Como você deve citar?}

SOUZA, Ricardo Abreu Lima de et al. Software educativo para seleção de materiais utilizando a metodologia de ASHBY. Cadernos UniFOA, Volta Redonda, n. 34, p. 35-45, ago. 2017. 


\section{INTRODUÇÃO}

Em engenharia, o projeto é um processo iterativo. Inicia-se com a definição de uma função, que pode ser uma simples caneta, até uma máquina complexa e cheia de partes, com diferentes tipos de materiais utilizados. Depois, utiliza-se conhecimentos técnicos, práticos, de experiência e teóricos, na criação de um projeto experimental. Posteriormente, refina-se essa ideia experimental com um processo sistemático que envolve a gestão de desenvolvimento de produtos, de acordo com normas e regras específicas ao critério do projetista [1].

De modo geral, desenvolver produtos ou projetos consiste em um conjunto de atividades por meio das quais se busca, a partir das necessidades do mercado e das possibilidades e restrições tecnológicas e, considerando as estratégias competitivas e de produto da empresa, chegar às especificações de projeto de um produto e de seus processos de produção, para que a manufatura seja capaz de produzi-lo [2].

Dentre as várias ferramentas adotadas para o desenvolvimento de um projeto, vale destacar o Processo de Desenvolvimento de Produtos (PDP), que é uma ferramenta na qual se identifica as necessidades do mercado, a fim de propor soluções que atendam a tais necessidades, por meio dos projetos e serviços relacionados [2].

Figura 1 - Processo de desenvolvimento de Produto [2].

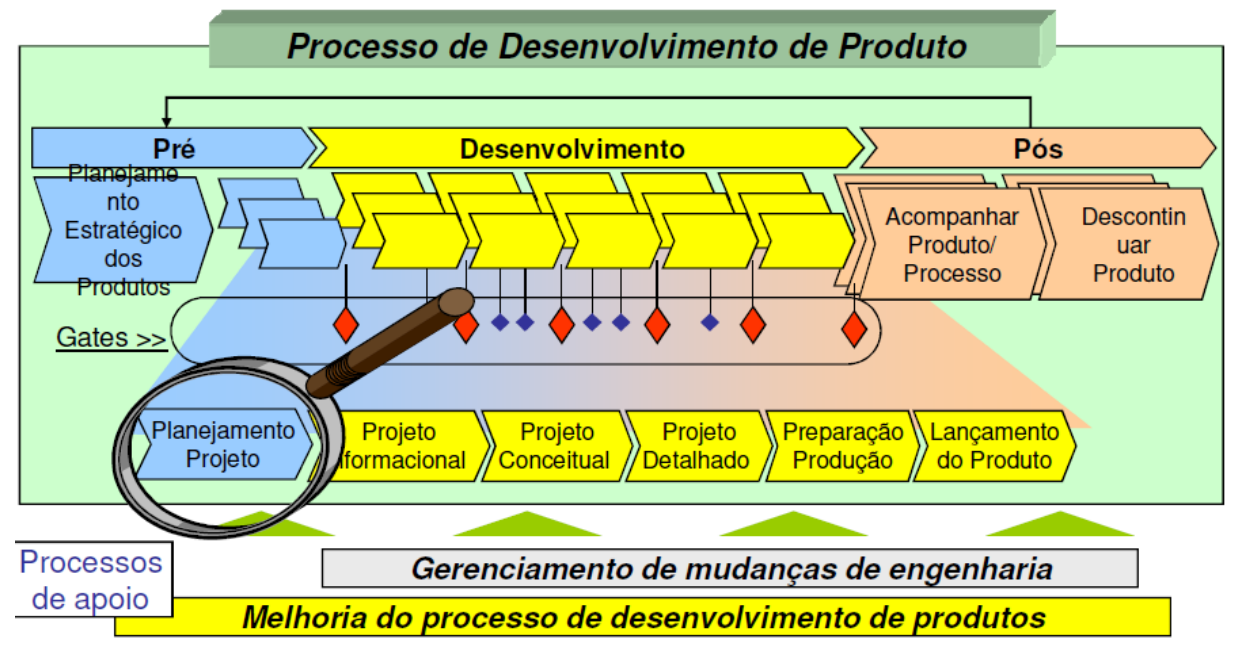

Fonte: dos autores, 2017.

Em sua fase inicial, são definidas as principais soluções e especificações do produto, para que sejam feitas as escolhas dos materiais, tecnologia, processo de fabricação e principais soluções construtivas, mesmo com possíveis alterações no decorrer do projeto [3]. Cada etapa do PDP, assim como as demais fases, possuem desmembramentos que garantem delimitação e precisão do projeto [2]. Os conceitos teóricos do PDP estimula o responsável pela criação e desenvolvimento do projeto a adquirir conhecimento, informações, detalhes e preparações, a partir dos subitens da etapa de desenvolvimento, como mostrado na figura 1.

Intimamente ligado ao conceito PDP está a seleção de materiais, que representa saber identificar a função do projeto, sua forma e o processo de fabricação que dará origem a tudo [4,5]. Para isso, foi escolhido a metodologia de Michael F. Ashby, professor e pesquisador conhecido por suas contribuições nas ciências e seleção dos materiais. 
Segundo Ashby, existem mais de 50.000 tipos de materiais à disposição de um profissional de engenharia. A grande questão e desafio para o engenheiro diante de um projeto é qual material escoIher com toda essa gama de possibilidades, que se divide em diversas propriedades e características diferentes. Qual será o material mais adequado? [6].

Além disso, o engenheiro deve levar em conta outros critérios para desempate ou análise, considerando também a metodologia de Ashby, que irá aumentar ou reduzir o custo final do produto a ser gerado, como o custo do material por kg e os diversos processos de fabricação existentes, nos quais seu consumo de energia são transferidos em forma de custo ao produto final $[3,7]$.

Diante desse paradigma, Ashby (2012) classificou, quanto ao seu entendimento, as propriedades dos materiais, de acordo com a tabela 1 para, posteriormente, dividir os materiais existentes em 6 famílias.

Tabela 1- Classes de propriedades.

\begin{tabular}{|c|c|}
\hline Aspecto econômico & Preço e disponibilidade \\
\hline & Capacidade de reciclagem \\
\hline Física geral & Densidade \\
\hline \multirow[t]{7}{*}{ Mecânica } & Módulo de elasticidade \\
\hline & Resistência à deformação e à tração \\
\hline & Dureza \\
\hline & Tenacidade à fratura \\
\hline & Limite de fadiga \\
\hline & Limite de resistência à deformação a quente (creep) \\
\hline & Característica de amortecimento \\
\hline \multirow[t]{3}{*}{ Térmica } & Condutividade térmica \\
\hline & Calor específico \\
\hline & Coeficiente de expansão térmica \\
\hline \multirow[t]{3}{*}{ Elétrica e magnética } & Resistividade \\
\hline & Constante dielétrica \\
\hline & Permeabilidade magnética \\
\hline \multirow[t]{3}{*}{ Interação ambiental } & Oxidação \\
\hline & Corrosão \\
\hline & Desgaste \\
\hline \multirow[t]{3}{*}{ Produção } & Facilidade no processamento \\
\hline & União \\
\hline & Acabamento \\
\hline \multirow[t]{3}{*}{ Estética } & Cor \\
\hline & Textura \\
\hline & Sensação táctil \\
\hline Óticas & Índice de refração \\
\hline \multirow[t]{2}{*}{ Propriedades ecológicas } & Energia incorporada \\
\hline & Pegada de carbono \\
\hline
\end{tabular}

Fonte: ASHBY E JONES, 2007

Assim, cada material pode ser agrupado em 6 famílias, consideradas por Ashby como as principais existentes no mundo dos materiais, como mostra a figura 2. 
Figura 2- As 6 famílias básicas [6].

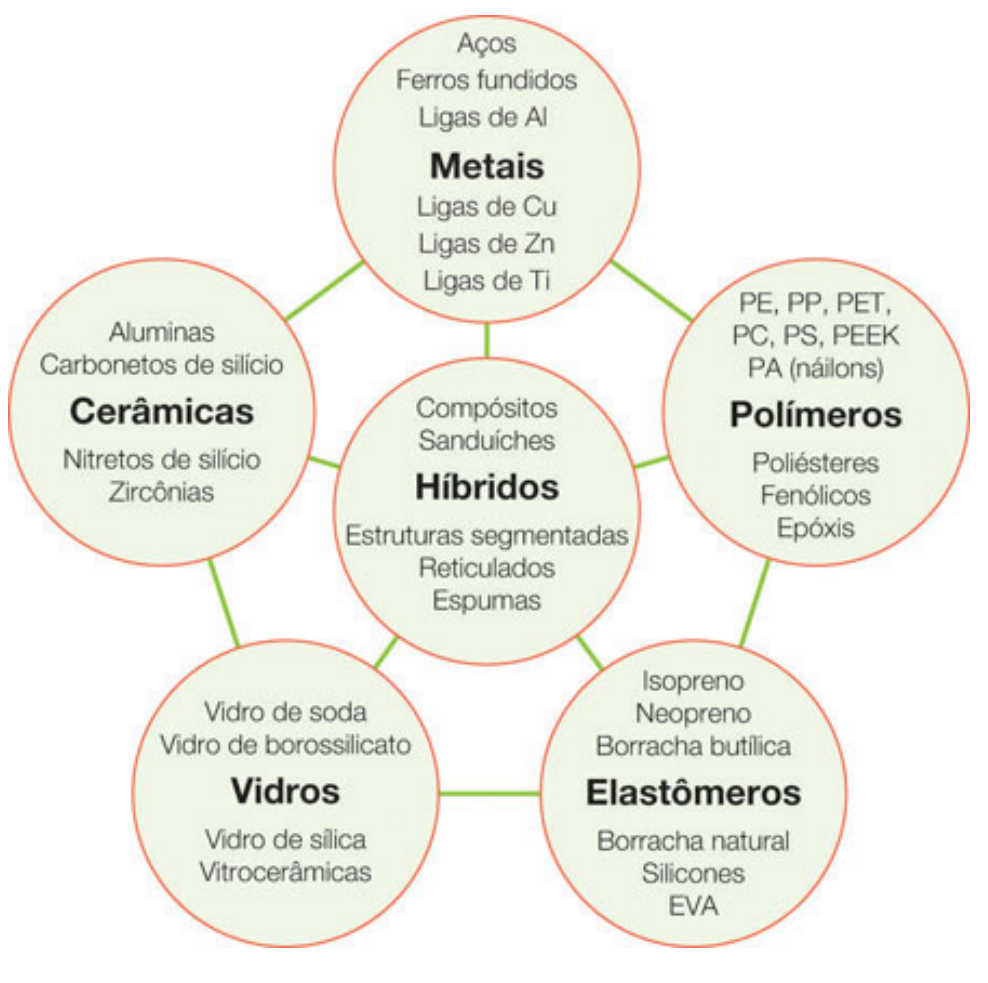

Fonte: dos autores, 2017.

Segundo Ashby, todas as informações, quando estruturadas, podem ser organizadas em banco de dados que, somada a outras fontes de informação, como catálogos, histórico de utilização do material e falhas, manuais entre outros, será o ponto de partida da seleção do material para o projeto [6].

A família dos materiais metálicos está presente em nosso cotidiano, apresentando-se, dessa forma, mais simples, como uma chave de roda para carro até projetos mais complexos [8]. Existem tantos metais diferentes que seria difícil memorizar todos, mas sabemos que a maioria é derivado aperfeiçoado das formulações básicas e, assim, conhecendo-se os metais genéricos, se conhecerá grande parte do que se precisa [3].

Os materiais metálicos são subdivididos em duas categorias: os ferrosos e os não ferrosos [9]. Cada uma dessas categorias possui uma extensa gama de produtos derivados de misturas diversas que formam diferentes características finais [10]. Por exemplo, as ligas metálicas, derivadas dos materiais não ferrosos, com adições especiais de componentes, são muito utilizadas, atualmente, por conferirem propriedades de acordo com a aplicação desejada [11, 12].

A metodologia para seleção de materiais criada por Ashby busca relacionar características, material, geometria e processo com funções matemáticas compreendidas na forma de índices de mérito, para avaliar o comportamento mecânico e suas funções, de acordo com a carga solicitada ou utilização do material, visando maximizar essas propriedades [4]. Assim, o material contendo o maior índice de mérito representaria a melhor escolha, salvo em casos em que outros quesitos, como custo, devem ser avaliados em conjunto como critério de desempate [6].

Esses índices permitem avaliar e listar todas as propriedades requeridas de um material, como a rigidez que relaciona o módulo de Young com a densidade, ao invés de simplesmente avaliar o módulo 
separadamente da densidade [13]. Isso proporciona garantir as características desejáveis do projeto, relacionando, no mínimo, duas das principais características requeridas [4].

Na prática, primeiramente, identificamos qual será o índice de desempenho, a partir da função em que o material será submetido junto à geometria aplicada. Então, é possível selecionar limiares para certas propriedades oferecidas em materiais que já são comumente mais utilizados, oferecidos por uma base de dados também criada por Asbhy [6]. Nesse banco de dados, a divisão por classe já nos permite realizar uma pré-seleção de materiais representativos, para, então, só trabalhar na classe relativa.

Finalmente, os materiais pré-selecionados são mostrados em um gráfico de duas dimensões, denominado diagrama de Ashby, que permite mostrar a gama de materiais de acordo com seus índices de mérito. Esses gráficos são construídos com base nas propriedades dos materiais, alocando-se, em seus eixos, duas propriedades que constituirão o índice de mérito para a respectiva exigência do projeto [6].

\section{MATERIAIS E MÉTODOS}

A metodologia desenvolvida ao longo deste trabalho se destina a analisar e compreender o método de Ashby, na aplicação de seleção de materiais, e seu potencial valor na Engenharia, utilizando-se gráficos e teoria na aplicação, em um estudo de caso para a família dos materiais metálicos, que verificarão o funcionamento e coerência da aplicação. Por meio da metodologia de Ashby, o projetista poderá selecionar o material de acordo com sua aplicação. A aplicação do método de Ashby, além de ser assertiva diante das grandes possibilidades de materiais a serem utilizados no projeto, também possui vantagens, como redução no custo do produto, redução do tempo de seleção do material a ser aplicado, possibilidade de outros materiais para serem analisados de acordo com a disponibilidade local, entre outros. Entretanto, conforme a metodologia proposta, não necessariamente apresentar-se-á materiais metálicos como a melhor escolha final.

De acordo com o objetivo desejado do projeto, fez-se uso, essencialmente, do software de desenvolvimento de algoritmos MATLAB (R2015b), no modo GUI (Graphical User Interface), para a elaboração de uma interface gráfica, na qual o usuário entrará com os dados do projeto e dos materiais que deseja utilizar e, posteriormente, a realização dos cálculos para elaboração dos índices de mérito de cada material.

A GUI do MATLAB dispõe de todos os recursos gráficos essenciais para criação de interfaces gráficas, desde as mais simples até as mais complexas, porém mantendo um "display" simples. Com o domínio da programação computacional, o programador tem a possibilidade de trabalhar na versão utilizada para este trabalho, que contém 14 funções gráficas como, botões push-pull, slider, check box, radio button, edit text, static text, list box, pop up menu, table, entre outros.

Cada botão específico exprime uma função que possui um script próprio exibido quando clicado em M-file Editor no menu superior da janela GUI. Por meio desse script, o programador consegue inserir ou alterar funções para o seu programa.

Por entender a necessidade de compreensão de cada etapa, optou-se por fazer uso de um fluxograma de processos (figura 3) para demonstrar detalhadamente o passo-a-passo do procedimento. 
Figura 3 -Fluxograma do programa (Autor, 2015).

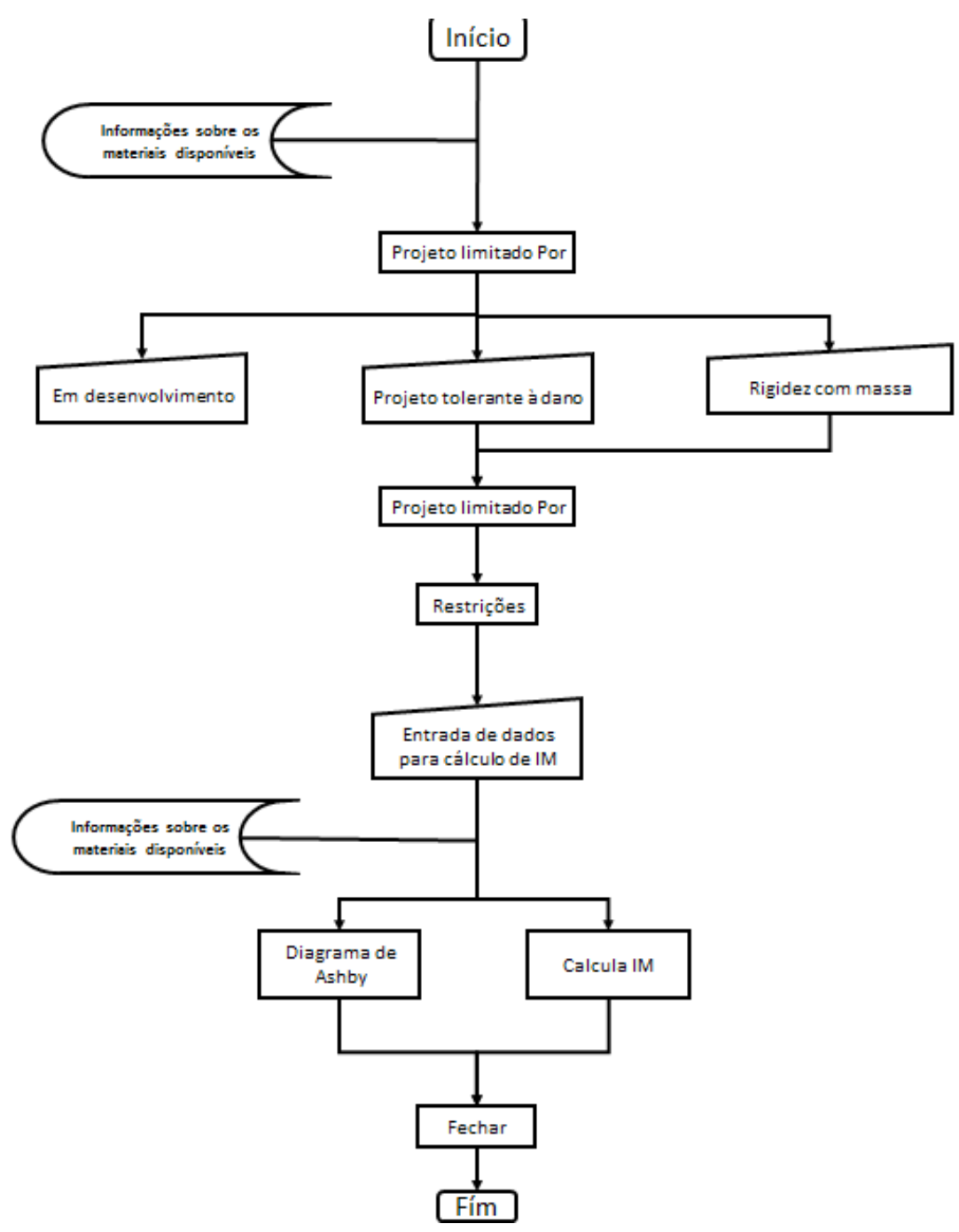

Fonte: dos autores, 2017.

\section{RESULTADOS E DISCUSSÕES}

\subsection{Revestimento do Suporte de Cabide}

O critério de seleção para a base do cabide levará em conta a seleção de materiais leves, rígidos e de baixo custo. Inicialmente, escolheremos a limitação do projeto oferecida pelo software a "Rigidez com Massa Mínima", na qual é a única opção que contempla o critério de seleção, figuras 4 e 5. 
Ricardo Abreu Lima de Souza | Alexandre Alvarenga Palmeira |Carlos Eduardo Abreu Lima de Souza Jorge João Ferreira de Souza Júnior I Duílio Norberto Ferronatto Leite

Figura 4 - Cabide de arame de aço com acabamento emborrachado

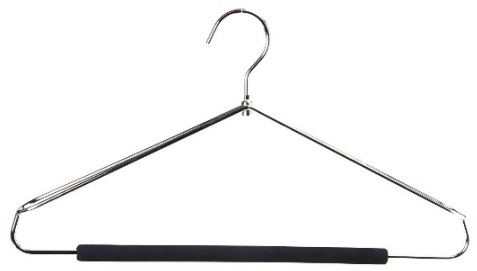

Fonte: (ASHBY, 2012)

Figura 5 - Seleção da limitação do Projeto.

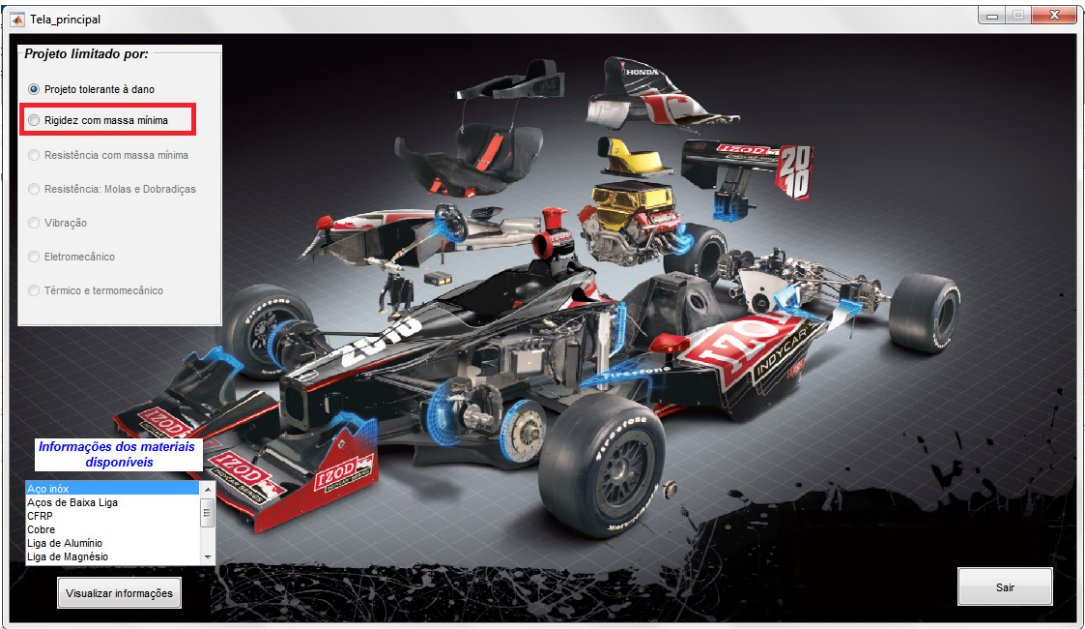

Fonte: (AUTOR, 2015)

A segunda opção é a função que o projeto exercerá, que, para esse caso, será "Viga carregada sobre flexão", dentro das opções disponíveis pelo software (figura 5).

Figura 6 - Seleção da função do projeto.

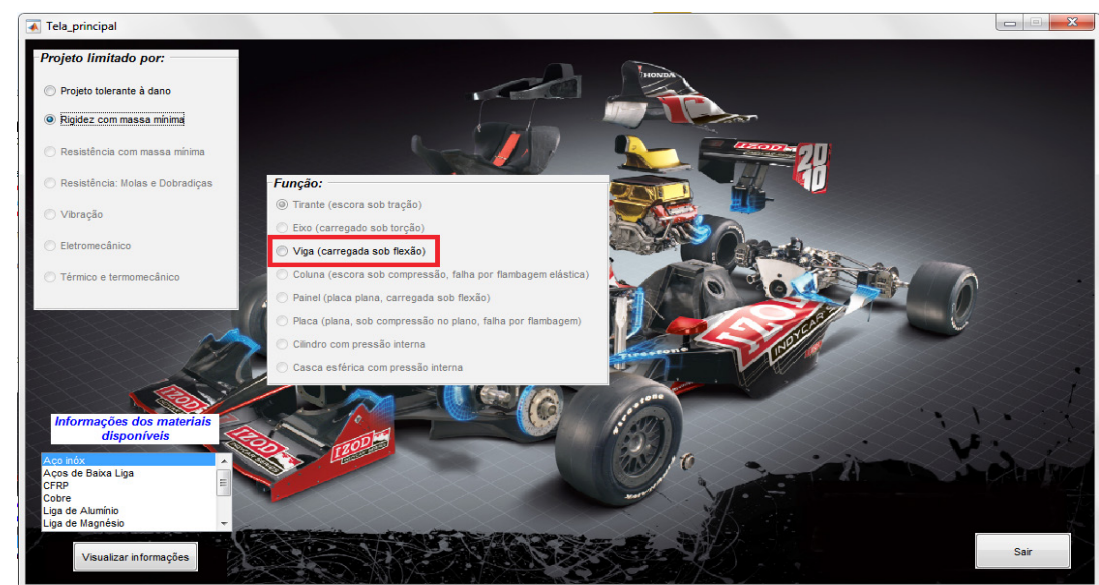

Fonte: (AUTOR, 2015) 
A terceira e última opção disponível pelo software será o bloco das restrições. Nessa etapa, o usuário deverá analisar quais parâmetros ele deve restringir, lembrando-se de que, para o caso do cabide, suas restrições são rigidez, comprimento e altura, tendo como liberdade a variação da largura da parede do tubo da base (figura 6).

Figura 7 - Seleção da restrição do projeto.

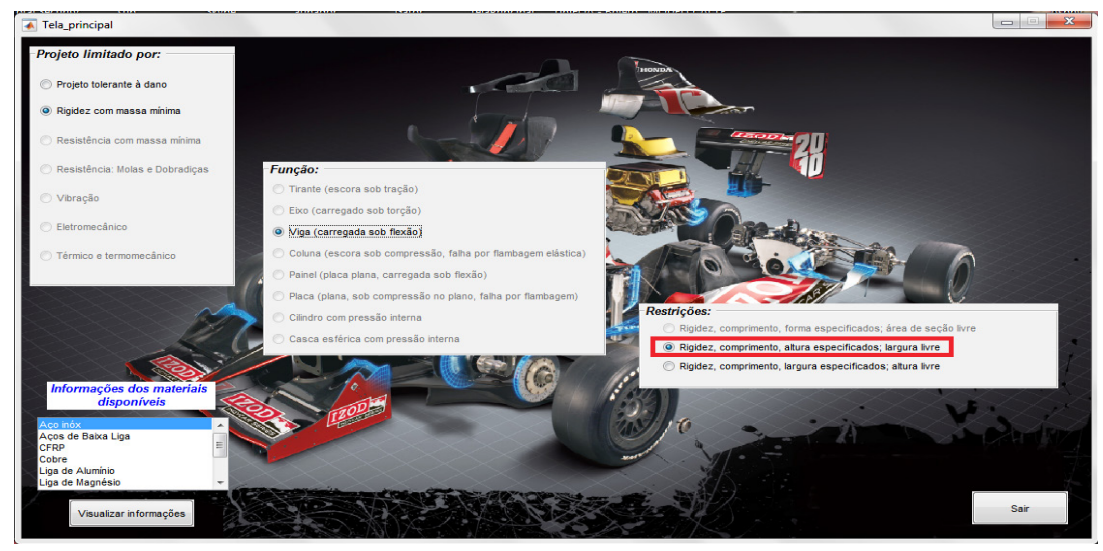

Fonte: (AUTOR, 2015)

Depois de selecionadas as restrições do projeto, o software provê a tela na qual o usuário entrará com os dados para o cálculo do índice de mérito e verificação do diagrama de Ashby. Nessa mesma tela, o usuário tem, à disposição, um banco de dados, contendo as informações necessárias para preenchimento. Caberá ao usuário a escolha de quatro materiais, para que seja realizado o cálculo do índice de mérito. Neste estudo de casos serão: Liga de Alumínio, Aço Inox, PVC e Polipropileno (figura 7).

Figura 8 - Tela dados para Índice de Mérito.

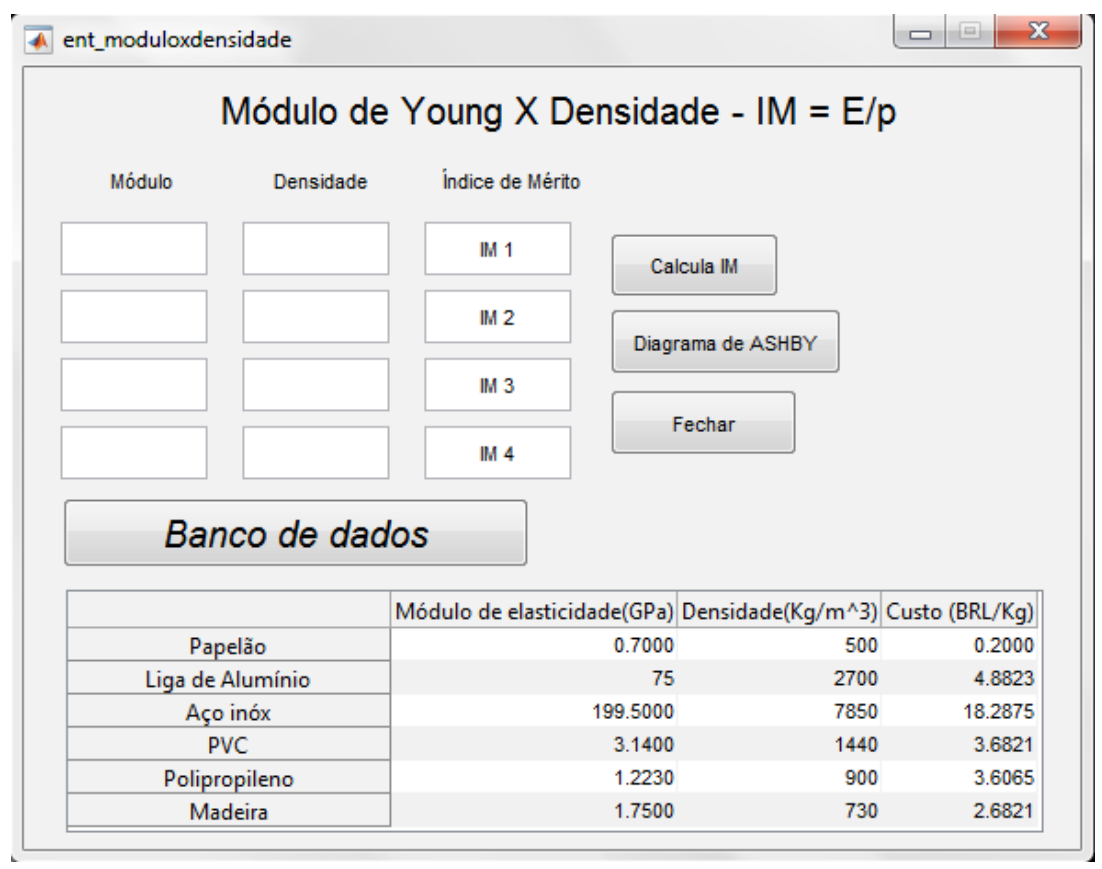

Fonte: (AUTOR, 2015) 
Depois da inserção dos dados, basta o usuário clicar em "Calcula IM" e os resultados serão exibidos ao lado. Agora, o usuário terá a opção de exibição do diagrama de Ashby com os pontos correspondentes e as propriedades solicitadas.

Os pontos representados no diagrama correspondem às coordenadas das propriedades dos materiais utilizados para o cálculo do Índice de Mérito (figura 8).

Figura 9 - Diagrama de Ashby, caso Cabide.

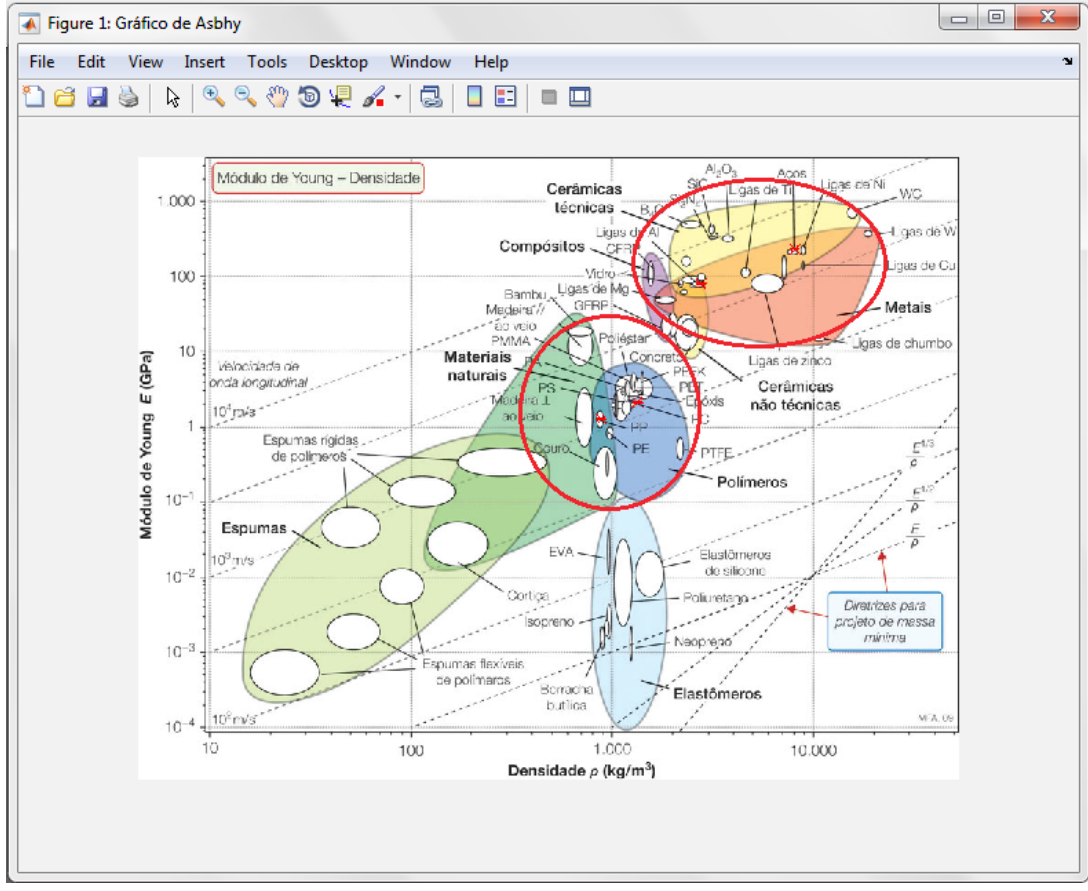

Fonte: (AUTOR, 2015)

A tabela 2 representa a ordenação dos resultados do cálculo do índice de mérito. Por meio dela, é possível observar que o material que corresponde a melhor seleção possui o maior índice de mérito, entretanto pode não representar a melhor escolha, pois, ao se utilizar uma massa relativamente grande, seu custo poderá fazer com que a escolha não se torne atrativa. De tal modo, sempre é necessário ter uma segunda opção em que se avalie a relação custo do material x massa utilizada para a fabricação. Para esse caso, a Liga de Alumínio e o Aço Inox correspondem as duas primeiras colocações, respectivamente, entretanto a liga de alumínio torna-se de alto custo, quando utilizada muita massa para a produção em série do produto. No caso do aço inox, é visível o elevado custo do material por kg.

Nesse caso o material que possui o menor custo por kg será o Polipropileno, que, mesmo sendo o último dos quatro utilizados para análise no programa, quando utilizado para produção em escala do produto, seu custo final será o menor, por ser um material de fácil manipulação, com um processo de fabricação simples e rápido e de baixo consumo energético. 
Tabela 2 - Resultado ordenado por índice de mérito.

\begin{tabular}{|c|c|c|}
\hline Material & I.M. Ordenado & Custo Material R\$/Kg \\
\hline Liga de Alumínio & 0,027778 & $\mathrm{R} \$ 4,8830$ \\
\hline Aço Inox & 0,025414 & $\mathrm{R} \$ 18,2875$ \\
\hline PVC & 0,002180 & $\mathrm{R} \$ 3,6821$ \\
\hline Polipropileno & 0,001359 & $\mathrm{R} \$ 3,6065$ \\
\hline
\end{tabular}

Fonte: (AUTOR, 2015)

\section{CONCLUSÃO}

Este estudo possibilitou compreender que, para se efetivar uma boa escolha de materiais para um determinado projeto de engenharia, há a necessidade de uma análise, apreciação e avaliação criteriosa da aplicabilidade, associada à funcionalidade e desempenho final do produto. Para tal, há de se que considerar as características que variam de acordo com a multiplicidade de materiais disponíveis no mercado.

Conclui-se, também, que o uso de ferramentas auxilia o engenheiro projetista, enquanto agente decisor, de forma a minimizar falhas e danos quantitativos e qualitativos no processo de tomada de decisão.

Conclui-se que, dentre as ferramentas de seleção apontadas pela literatura, o método de Seleção de Materiais por Ashby mostra-se como muito apropriado para o uso em projetos mecânicos de fabricação, com o intuito de alinhar o custo-benefício do processo. Entretanto, há sempre a necessidade de utilizar um segundo ou terceiro ponto para desempate na seleção do material e, dentre os mais recomendados, está o custo do material por kg e o processo de fabricação que, indiretamente, agrega custo ao produto final.

O software possibilita o aprendizado do método de Seleção de Materiais por Ashby por meios acadêmicos e afins, oferecendo uma execução dinâmica e interativa que facilita e torna autosugestiva a utilização do produto.

Em síntese, os resultados da criação do referido software com intuito educacional conseguiu atender à necessidade de criação de uma ferramenta que auxilia e que é mais atrativa e dinâmica para o entendimento do conteúdo em questão.

Portanto, a metodologia proposta neste trabalho permitiu ampliar de forma significativa as ferramentas de auxílio em sala de aula para superar um dos desafios enfrentados pelo engenheiro na sua atividade ocupacional: o processo de seleção de materiais. 


\section{REFERÊNCIAS}

[1] GROOVER, M. P. Introdução aos processos de fabricação. 1. ed. [S.I.]: LTC, 2014.

[2] ROZENFELD, H. et al. Gestão de desenvolvimento de produtos: uma referência para a melhoria do processo. 1. ed. São Paulo: Saraiva, v. I, 2006.

[3] COLLINS, J. Porjeto mecânico de elementos de máquinas. 1. ed. São Paulo: LTC, v. I, 2005.

[4] ASHBY, M. F.; JONES, D. R. H. Engenharia de materiais: uma introdução a propriedades, aplicações e projeto. 3. ed. [S.I.]: CAMPUS, v. 2, 2007.

[5] ASHBY, M. F.; JONES, D. R. H. Engenharia de materiais: uma introdução a propriedades, aplicações e projeto. 3. ed. [S.I.]: Campus, v. 1, 2007.

[6] ASHBY, M. F. Seleção de materiais no projeto mecânico. 4. ed. Oxford: Elsevier, v. 1, 2012.

[7] JUVINALL, R. C.; MARSHEK, K. M. Fundamentos do projeto de componentes de máquinas. 4. ed. São Paulo: LTC, 2008.

[8] DIETER, G. E. Materials selection and design. 1. ed. New York: ASM International, v. XX, 1997.

[9] CHIAVERINI, V. Aços e ferros fundidos. 7. ed. São Paulo: [s.n.], v. I, 2002.

[10] GARCIA, A.; SPIM, J, A.; SANTOS, C. A. Ensaio dos materiais 1. ed. Rio Janeiro: LTC, v. I, 2000.

[11] PADILHA, A. F. Materiais de engenharia: microestrutura e propriedades. 1. ed. Curitiba: Hemus, v. I, 2000.

[12] CALLISTER JR, W. D. Ciência e engenharia de materiais: uma introdução. 5. ed. São Paulo: LTC, v. I, 2002.

[13] KLOCKE, F. Manufacturing process 1: Cutting. 1. ed. Aachen: Springer, v. I, 2010. 